\section{Reactivation of fetal hemoglobin in thalassemia and sickle cell disease}

\section{Sandro Eridani, Francesca Avemaria, Andrea Mosca}

Dipartimento di Fisiopatologia Medico Chirurgica e dei Trapianti, Università degli Studi di Milano, Italy

\section{Abstract}

Considerable attention has been recently devoted to mechanisms involved in the perinatal hemoglobin switch, as it was long ago established that the survival of fetal hemoglobin $(\mathrm{HbF})$ production in significant amount can reduce the severity of the clinical course in severe disorders like $\beta$-thalassemia and sickle cell disease (SCD). For instance, when $\beta$-thalassemia is associated with hereditary persistence of fetal hemoglobin (HPFH) the disease takes a mild course, labeled as thalassemia intermedia. The same clinical amelioration occurs for the association between HPFH and SCD. As for the mechanism of this effect, some information has been obtained from the study of natural mutations at the human $\beta$-globin locus in patients with increased $\mathrm{HbF}$, like the Corfu thalassemia mutations. Important evidence came from the discovery that drugs capable of improving the clinical picture of SCD, like decitabine ad hydroxycarbamide, are acting through the reactivation, to some extent, of $\mathrm{HbF}$ synthesis. The study of the mechanism of action of these compounds was followed by the identification of some genetic determinants, which promote this event. In particular, among a few genetic factors involved in this process, the most relevant appears the BCL11A gene, which is now credited to be able to silence $\gamma$-globin genes in the perinatal period by interaction with several erythroid-specific transcription factors and is actually considered as a barrier to $\mathrm{HbF}$ reactivation by known $\mathrm{HbF}$ inducing agents.

Epigenetics is also a player in the process, mainly through DNA demethylation. This is certified by the recent demonstration that hypomethylating agents such as 5-azacytidine and decitabine, the first compounds used for $\mathrm{HbF}$ induction by pharmacology, act as irreversible inhibitors of demethyltransferase enzymes. Great interest has also been raised by the finding that several micro-RNAs, which act as negative regulators of gene expression, have been implicated in the progression of globin gene expression and, particularly, in the reactivation of $\gamma$-globin gene expression associated with increased HbF synthesis. Probably, this reactivation is achieved by post-transcriptional inhibition of BCL11A expression.

Finally, attention is presently focused on a recently discovered BCL11A enhancer, essential for erythroid expression of BCL11A, which might become a therapeutic target for genome engineering in the $\beta$-hemoglobinopathies as its disruption affects only the erythropoietic lineage, without hurting other cell or tissue compartments.

\section{Introduction}

Recent developments have given new impetus to the search to induce a significant recovery of fetal hemopoiesis in adults, as this could be of significant benefit for patients, in which the normal hemoglobin situation has been affected either by a reduction of its $\beta$-globin component, like in $\beta$-thalassemia, or by an aminoacid substitution in the same $\beta$-globin, as in sickle cell disease (SCD). Support for this research is given by the realization of the clinical advantage gained in these patients by treatments, which induce a considerable reactivation of the same fetal hemoglobin (HbF).

Aim of the present study is to review the past experience in this field as well as discuss the most recent acquisitions on the genetic and molecular mechanisms, which govern the perinatal switch from fetal to adult $\mathrm{Hb}$, including the possibility to reverse the switch and generate a return to prenatal erythropoiesis.

\section{Fetal hemoglobin in adult life}

There are many disparate conditions, in which a higher level of $\mathrm{HbF}$ than normal can be found in adults, ranging from hereditary disorders to acquired ones, as well as from blood diseases to non-hematological situations (Table 1). It is known indeed that, as a result of the switch to $\mathrm{HbA}$ in early life, only a tiny fraction of $\mathrm{HbF}$ is normally present in the majority of adults. ${ }^{1}$ Traditionally, the switch was ascribed to a variety of mutations in the $\beta$ globin cluster, leading for instance to a uniform increase of $\mathrm{HbF}$ [pancellular hereditary persistence of fetal hemoglobin (HPFH)], a condition allowing a normal way of life, or leading to a non-uniform distribution of $\mathrm{HbF}$ termed as heterocellular HPFH or Swiss HPFH from an original report, ${ }^{2}$ and based on the coexistence of two population of red cells: one with a high content of $\mathrm{HbF}$ (so called F cells), and another with a negligible amount of the same. ${ }^{3}$

Different mechanisms have presently been proposed responsible for persistence of $\mathrm{HbF}$ in adults, as a series of investigations on
Correspondence: Andrea Mosca, Dipartimento di Fisiopatologia Medico Chirurgica e dei Trapianti, via Fratelli Cervi 93, 20090 Segrate (MI), Italy.

Fax: +39.02.9998.7559.

E-mail: andrea.mosca@unimi.it

Key words: sickle cell disease, hemoglobin $\mathrm{F}$, determinants, inducers.

Received for publication: 16 December 2013 Accepted for publication: 19 March 2014

This work is licensed under a Creative Commons Attribution 3.0 License (by-nc 3.0).

(C) Copyright S. Eridani et al., 2014

Licensee PAGEPress, Italy

Thalassemia Reports 2014; 4:2196

doi:10.4081/thal.2014.2196

Mediterranean and African populations revealed a marked heterogeneity of situations. ${ }^{4,5}$ For instance, in some cases of $\delta$ $\beta$-thalassemia, $\mathrm{HbF}$ persistence is due to deletions of variable extent within the $\beta$ globin cluster, with coinheritance of genetic determinants able to sustain a continuous production of $\gamma$ chains which bind the excess $\alpha$ chains ${ }^{6}$ in other cases, individuals with increased $\mathrm{HbF}$ in adult-type erythroid cells show mutations in the promoters of both the $\mathrm{G} \gamma$ and $\mathrm{A} \gamma$ genes and have been referred as having the non-deletional form of HPFH, as compared to those with deletion-type HPFH. ${ }^{7}$

Recently, interesting data were obtained in a study of two novel mutations in three Italian patients with elevated $\mathrm{HbF}$ values without an elevated $\mathrm{HbA}_{2}$ and with normal hemoglobin parameters. Two probands (mother and son) carried a $-197 \mathrm{C}>\mathrm{T}$ transition, while a single individual showed a $-113 \mathrm{~A}>\mathrm{G}$ transition on the distal CCAAT box of the A $\gamma$ gene; no other abnormalities were present in both $\gamma$-gene promoters and the changes were located on regulatory sequences. Furthermore, a critical evaluation of many conditions has been advocated switching from criteria based on clinical phenotype to those based on genotype: most situations termed as HPFH are now considered just plain $\beta$-thalassemia deletions of mild or intermediate character, combined with $\beta$-thalassemia defects: the expression of $\gamma$-genes in these cases is sufficient to maintain a good level of hemoglobin. ${ }^{8}$ It is also stressed that the diagnosis of HPFH should be only applied to those cases not associated with common polymorphisms, like the $-158 \mathrm{C}>\mathrm{T}$ (or Xmn-I); moreover, such situations induce $\mathrm{HbF}$ expression during erythropoietic stress, with a beneficial effect on the phenotype of $\beta$-thalassemia major or intermedia, and also enhance the therapeutic efficacy of hydroxyurea. ${ }^{9}$

The association of high $\mathrm{HbF}$ with hemoglo- 
binopathies has been actually the subject of a variety of clinical studies, which have shown different interactions with both Thalassemia and SCD. Among many observations on affected families, an interesting problem is represented by early descriptions of high-HbF variety of $\beta$-thalassemia, characterized by a mild course and such high levels of $\mathrm{HbF}$ that a definition of $\delta$ - $\beta$-F-thalassemia was applied; this phenomenon was later interpreted as due to coinheritance of a genetic determinant able to sustain a continuous production of $\gamma$-chains in adult life, thereby reducing the extent of the $\alpha /$ non- $\alpha$-chain imbalance. ${ }^{10}$ This also applies to cases of homozygous HPHF with $100 \% \mathrm{HbF}$ and no $\mathrm{HbA}$ or $\mathrm{A}_{2}$, which are considered by Weatherall extremely mild forms of $\beta-\delta$-thalassemia, in which defective $\beta$-chain synthesis is compensated by increased HbF synthesis. ${ }^{11}$

About the association with SCD, a link between the increase of $\mathrm{HbF}$ and the SCD phenotype was identified long ago in a population of Saudi Arabia with a significant increase of heterocellular $\mathrm{HbF}$ in SCD patients. ${ }^{12}$ More recent investigations have shown that in Middle East Arab countries the clinical picture of SCD expresses two distinct forms, benign and severe, related to distinct $\beta$-globin gene haplotypes, referred to as the Saudi-Indian and the Benin haplotypes: if the HbS mutation takes place on a chromosome carrying the Saudi-Indian haplotype the $\mathrm{HbS}$ mutation generally gives rise to a mild clinical form with an elevated HbF; the same mutation occurring on a chromosome carrying the Benin haplotype is generally associated with lower $\mathrm{HbF}$ levels and a severe disease. Elevated $\mathrm{HbF}$ levels thus play a clear role in determining the clinical picture, while the association with $\alpha$-thalassemia may also reduce the severity of the disease. ${ }^{13}$

\section{Effects of fetal hemoglobin presence}

It has already been mentioned that early research showed how HbF levels are a major predictor of survival in SCD, and how the risk of early death appears inversely associated with $\mathrm{HbF}$ levels. ${ }^{14}$ The beneficial effect of $\mathrm{HbF}$ includes the inhibition of $\mathrm{HbS}$ polymerization and a dilution of $\mathrm{HbS}$ concentration in red blood cells by its very presence. This leads obviously to improved survival and better way of life in SCD patients with an increased ability of $\mathrm{HbF}$ production.

A recent study, performed in the largest documented series of compound heterozygous subjects for $\mathrm{HbS}$ and deletional $\beta$-thalassemia defects confirmed that these patients, with a uniformly distributed $\mathrm{HbF}$ level at around $30 \%$, have a benign clinical course similar to those with sickle cell trait and $\mathrm{HbA}$ levels of around $60 \%$. All patients in this group were indeed followed in the outpatient clinic once a year only, did not require any therapeutic intervention and even penicilin prophilaxis was discontinued. ${ }^{15}$

As far as $\beta$-thalassemia is concerned, it is known that infants with $\beta$-thalassemia biochemical imprint show the related symptomatology only after the decrease in $\mathrm{HbF}$ production, namely when the normal fetal-to-adult hemoglobin switch takes place. Moreover, it has been established that patients with those rare forms of $\beta$-thalassemia with deletions causing hereditary persistence of $\mathrm{HbF}$ have a relatively benign clinical course thanks to elevated levels of this hemoglobin. ${ }^{16}$

The role of increased $\mathrm{HbF}$ synthesis as a beneficial factor in some Hb-pathies became also evident in a group of homozygous $\beta^{0}$-thalassemia intermedia patients who have a mild

Table 1. Conditions affecting hemoglobin F levels.

Hereditary diseases

Thalassemia syndromes (homozygous $\beta$ thalassemia, heterozygous $\beta$ thalassemia, $\delta-\beta$ thalassemia, homozygous and heterozygous)

Other hemoglobinopathies (hereditary persistence of hemoglobin F, sickle cell anemia, hemoglobin C, hemoglobin E, hemoglobin Lepore syndrome, some unstable hemoglobins)

Hereditary spherocytosis

Hemoglobin variants with retention time similar to that of hemoglobin $\mathrm{F}$

Acquired conditions

Non-neoplastic blood disorders

Pernicious anemia

Sideroblastic anemia

Pure red cell aplasia

Refractory normoblastic anemia

Aplastic anemia

Paroxysmal nocturnal hemoglobinuria

Recovery from bone marrow transplant

Neoplastic blood disorders

Acute leukemias

Erythroleukemia

Juvenile chronic myeloid leukemia

Marrow neoplastic metastases

Treatment-related situations

Antileukemic chemotherapy

Therapy with hydroxyurea, aza-deoxycytidine, butyrates and erythropoietin

\section{Miscellaneous}

Stress erythropoiesis

Pregnancy

Hyperthyroidism

Chronic renal disease

Trisomy 13 (Palau syndrome)

Hepatoma

Data modified from Menzel et al., 2007.40 
disease despite the absence of hemoglobin A $\left(\alpha_{2} \beta_{2}\right)$. In this case the reduced clinical severity was due either to the presence of the abovementioned X-mn-1 polymorphism, which is able to increase the $\mathrm{G} \gamma$ chain output, or to coinheritance of $\alpha$-thalassemia. ${ }^{17}$

\section{Pharmacological induction of fetal hemoglobin}

Such approach has been attempted since the 1980 s, ranging from drugs like 5 -azacytidine and its derivative, decitabine to a series of compounds like hydroxycarbamide and a number of histone deacetylase inhibitors like butyrate. It was indeed in the early ' 80 s that 5 aza-cytidine was shown able to re-induce production of $\mathrm{HbF}$ in adults, as well as in experimental animals. ${ }^{18}$ Years later a derivative of azacytidine, namely deoxy-azacytidine or decitabine (DAC), was found effective in reactivating production of fetal $\mathrm{Hb}$ and was therefore started in regular trials on SCD patients. It was also been observed that adult SCD patients with multiple complications who did not respond adequately to other treatments like hydroxycarbamide had less vaso-occlusive events and increased hemoglobin levels following treatment with DAC. ${ }^{19}$

Hydroxyurea (HU), or hydroxycarbamide (HC), known for long time as an oral, well-tolerated drug for some myeloproliferative disorders, remains at present the most reliable drug to be employed for reactivating $\mathrm{HbF}$ production. A major activity was noted in the presence of Xmn-1 polymorphism. ${ }^{20}$ Predictably, bone marrow suppression was observed after long treatment, but such effect is reversible.

It has to be noted however that not all patients receiving $\mathrm{HC}$ show a response to treatment. Particularly, little clinical improvement is observed in SCD patients with coinherited $\alpha$-thalassemia ( $\alpha$ Thal-SCD), probably due to an elevated hematocrit and a subsequent increase in vaso-occlusive events, confirmed by a rise in cell-free DNA, a marker of tissue damage. ${ }^{21}$ As for the mechanism of action of HC, it was early shown to be mediated through the activation of soluble guanylilcyclase, ${ }^{22}$ while latest research has focused on its effects on erythroid gene expression. An expression analysis study of reticulocyte RNA from children with SCD and treated with HC has indeed shown that this compound affects a great number of erythroid genes, including BCL11A and SOX6, which are considered negative regulators of fetal $\mathrm{Hb}$ levels. ${ }^{23}$

\section{Determinants of fetal hemoglobin production}

It has to be reminded that hemoglobin production in early life is subject to a couple of switching events. The first event occurs in human beings during the transition from yolk sac to fetal liver erythropoiesis: this is the change from embryonic hemoglobins and to $\alpha$ and $\gamma$ globins, which form fetal $\mathrm{Hb}\left(\alpha_{2} \gamma_{2}\right)$. In the perinatal period a second switch takes place, with the tapering of $\mathrm{HbF}$ production and synthesis of adult $\mathrm{HbA}$ so that a minimal amount of $\mathrm{HbF}$, as beforesaid, is present in a few erythrocytes in normal adults. ${ }^{1}$

As far as the second switch between fetal and adult hemoglobin, object of the present review, a remarkable amount of research has been going on in the last 20 years to identify genetic mechanisms that control the production or the inhibition of $\mathrm{HbF}$, apart from the obvious inheritance parameters. The outcome of these studies has been the realization that the $\mathrm{HbF}$ to $\mathrm{HbA}$ switch is a complex process and that many factors of genetic (or epigenetic) characters are involved (Table 2).

Great attention was obviously devoted to possible molecular bases of HPFH as different mechanisms may be of relevance in the process of the perinatal globin switch. Experimental studies, on adult transgenic mice for the $\beta$-globin locus have identified two elements, termed Enh and F, located 3' of the A $\gamma$ gene, whose deletion induces high levels of A $\gamma$ gene expression. ${ }^{6}$ Another study on erytroyd cells from HPFH carrying human subjects found a down-regulation of the transcription factor ZHX2. ${ }^{24}$

Some information has been obtained from the study of natural mutations at the human $\beta$ globin locus in patients with increased HbF. A typical case in point has been the investigation on heterozygotes and homozygotes with the Corfu thalassemia mutation. Two mutations are present on the Corfu chromosome: the first one a 7.2-kb deletion removing part of the $\delta$ globin gene and upstream flanking sequences, the second one a splice site mutation in intron 1 of the $\beta$-globin gene. Homozygotes for the Corfu deletion have very high levels of fetal $\mathrm{Hb}$ and a mild disease..$^{25}$

These results indicate that the Corfu deletion alone can almost completely reactivate $\gamma$ globin expression in adult-type cells. It is unclear whether the persistence of human $\gamma$ globin and $\mathrm{HbF}$ in patients with the Corfu, $\delta-\beta$ thalassemia, or HPFH deletions also prompts a normal stage-specific switching in late fetal life. This represents anyway strong evidence in humans that intergenic $\gamma-\delta$ sequences alone can regulate the activity of $\mathrm{HbF}$ in adult-type cells, and perhaps play a role in normal human hemoglobin switching as well. ${ }^{26}$

Among a series of genetic sites playing a role on the activation of $\mathrm{HbF}$, three major quantitative trait loci (QTL) have however emerged from genome-wide association studies. These loci contain a set of five common single nucleotide variants that predict the clinical severity of SCD and at least one of these single nucleotide polymorphisms (SNPs) may also affect the clinical outcome in $\beta$-thalassemia. ${ }^{27}$

A first locus was identified since the early ' $90 \mathrm{~s}$, when it was found that the XmnI site, 5 to the $\mathbf{G} \gamma \gamma$ gene, seemed correlated with $\gamma$-globin expression. ${ }^{28}$ It was actually shown that a common sequence variation (T-C) at position 158 upstream of the $\mathrm{G} \gamma$-globin gene, detectable by the restriction enzyme XmnI (the XmnIG), not only affects the G-y/A-y ratio of hematologically normal individuals, but also increases the production of $\mathrm{HbF}$ in those cells which retain the potential to do so in adult life. The effect appears to be modest but certainly is quite relevant for the diagnosis and genetic analysis of heterocellular HPFH. ${ }^{29}$

While some evidence for sites on chromosome $8 \mathrm{q}$ affecting the developmental switch from $\mathrm{HbF}$ to $\mathrm{HbA}^{30}$ has not been validated in recent genome-wide association studies, ${ }^{31}$ a second QTL for fetal hemoglobin production has now been firmly established on cromosome 6q23. This was first observed in an Asian-Indian population, in which there was an association between $\beta$-thalassemia and $\mathrm{HPFH},{ }^{32}$ and later confirmed in a population of Northern European ancestry. The QTL includes several genes like $H B S 1 L$, a member of the GTP-binding protein family that is expressed in erythroid progenitor cells. In a high-resolution association study, multiple genetic vari-

Table 2. Determinants of hemoglobin F production.

\begin{tabular}{lc}
\hline 1) Quantitative trait loci & Chromosome \\
Xmn1-HBG2 & 11 \\
HMIP (HBS1L-MYB intergenic polymorphism) & 6 \\
BCL11A & \\
2) Erythroid-specific genes (KLFl, GATAl and others) & \\
3) Epigenetic modifications (e.g. state of DNA methylation) & \\
4) Micro-RNA's & \\
5) BCL11A enhancer
\end{tabular}


ants were identified within and 5' to HBS1L at $6 q 23$, strongly associated with F-cell levels but, while mRNA levels of HBS1L and MYB are positively correlated in erythroid precursors grown in vitro, only HBS1L expression correlates with high F-cell alleles, suggesting a key role for the HBS1L-related genetic variants in $\mathrm{HbF}$ control. ${ }^{33}$

At about the same time, genome wide association studies led to the identification of a new HbF-associated locus on chromosome 2, located within the gene BCL11A.$^{34}$ BCL11A, a zinc-finger transcription factor (B-cell lymphoma/leukemia 11A), is considered indispensable for normal lymphoid development in humans ${ }^{35}$ and is also associated with lymphoid malignancies. ${ }^{36}$

Experimental investigation support the role played by this gene in the hemoglobin switch. Deletion of BCL11A in mice carrying a human $\beta$-globin cluster transgene leads to profound delay in globin switching and impaired $\mathrm{HbF}$ silencing in adult erythroid cells. Furthermore, previously silenced $\gamma$-globin genes can also be reactivated by loss of BCL11A in adult animals. ${ }^{37}$ It was also found that inactivation of BCL11A alone is sufficient to ameliorate the hematologic and pathologic defects associated with SCD through high level HbF induction in mice carrying the human $\beta$-globin gene cluster as a yeast artificial chromosome transgene. ${ }^{38}$

On the clinical side a population study suggested that BCL11A variants influence $\mathrm{HbF}$ levels in non-anemic Caucasians from a European twin study. In this study is of interest that a $\mathrm{C}$ variant in the BCL11A locus was found more frequent both in subjects with heterocellular HPFH (detected by $\beta$-thalassemia screening) and in homozygotes $\beta^{0}$-thalassemia with a mild phenotype, so the imbalance of hemoglobin production was partly counteracted by the augmentation of $\mathrm{HbF}$ levels. ${ }^{39}$ It was later demonstrated that, among the factors able to modify the phenotype of homozygous $\beta$-thalassemia by increasing $\mathrm{HbF}$ levels, the SNP variant in the BCL11A gene contributed more strongly than the HBS1L-MYB locus or the coinheritance of $\alpha$-thalassemia, in agreement with previous observations that identified the $2 \mathrm{p} 15$ locus as the major modifier of $\mathrm{HbF}$ levels in healthy populations. It is of interest that in this work the parameter used to classify genetic modifiers was time to first transfusion, an event that characterizes disease severity. ${ }^{40}$

Considerable progress has also been achieved by studies on the role of other erythroid-specific gene repressors or activators of $\mathrm{HbF}$. Special interest relevance was given to the transcription factor KFL-1, a protein encoded by the KFL-1 gene, which binds to the BCL11A promoter and thus can activate the silencing action of BCL11A on HbF production. Recently, it has been found that many KFL-1 mutations are associated with increased $\mathrm{HbF}$ levels in ethnically diverse patients and that they can induce a significant improvement in the clinical course of hemoglobinopathies in malarial regions. ${ }^{41}$

More interesting data were recently published about the role of interacting partner proteins of BCL11A. It was confirmed that BCL11A acts within multiprotein complexes, consisting of transcriptional co-repressors and chromatin-modifying subunits. The knockdown of several BCL11A interacting proteins induces $\mathrm{HbF}$ expression in primary human erythroid cells. Besides the reactivation of $\mathrm{HbF}$ expression, it was found that depletion of such interacting proteins impairs erythroid cell maturation ex vivo, as revealed by reduced expression of erythroid cell surface markers CD71 and CD235a. It was also observed that a depletion of BCL11A interacting proteins results in variable effects on the synthesis of total human $\beta$-like globin mRNAs. The deletion of some genes has little effect, but getting rid of other genes led to a greater than twofold increase (NCOR1 and KDM5D) or decrease $(K L F 1, S O X 6)$ in expression of total $\beta$-like globin mRNA, suggesting that their gene products are required for normal erythroid development. ${ }^{42}$

It was also established that BCL11A interacts with several erythroid regulators, including GATA1, FOG1, and SOX6, and with the nucleosome remodeling deacetylase complex (NuRD), which consists of several enzymatic subunits, including the ATPase subunit Mi$2 \beta,{ }^{43}$ as well as the histone deacetylases HDAC1 and HDAC2, identified as HbF inducers by a chemical genetic screen. ${ }^{44}$ Depletion of $\mathrm{Mi}-2 \beta$ results in a profound increase in $\gamma$-globin expression in primary human erythroid cells, although the degree of $\gamma$-globin induction is substantially less than seen with BCL11A deficiency. Furthermore, depletion of HDAC1 and HDAC2 reactivates $\gamma$-globin expression in primary human erythroid cells. These results provide altogether strong support for an important role of several enzymatic subunits within the NuRD complex in globin expression. It can be reminded that HDAC inhibitors are among the agents suggested for clinical treatment of SCD. ${ }^{45}$

Other events not to be underestimated as regulatory mechanisms are epigenetic changes, such as histone modifications and DNA methylation. Histone modifications by acetylation, methylation, phosphorylation, sumoylation, and ubiquitination and DNA methylation on $\mathrm{CpG}$ residues are among the most important epigenetic mechanisms. ${ }^{45}$ DNA methylation is apparently the best-characterized epigenetic modifier of $\mathrm{HbF}$ level. Methylation of $\mathrm{CpG}$ dinucleotides within the $\gamma$ globin promoter has been associated with gene silencing by inhibiting the transcription of $\gamma$ globin genes in adult bone marrow. Compared with fetal erythroid cells, the $\gamma$-globin promoter region of adult erythroid cells is highly methylated, and this hypermethylation has been inversely correlated with $\mathrm{HbF}$ expression. ${ }^{46}$

Methylation is of particular interest for understanding the reactivation of $\mathrm{HbF}$ because hypomethylating agents, like 5 -azacytidine and decitabine, were among the first compounds used for $\mathrm{HbF}$ induction by pharmacology. They are now believed to act as irreversible inhibitors of two demethyltransferase enzymes DMTN 1 and DMT3 and are presently tried for treating some neoplastic conditions as well. ${ }^{47}$

As for the best available drug to restore $\mathrm{HbF}$ production, HU, an early study suggested an action for significant changes in the gene expression pattern, with activation of transcription factors and pathways involved in signal transduction, eventually leading to an increase of globin gene expression. ${ }^{48}$ There is however, even in the case of HU-induced expression of $\mathrm{Hb}$, some evidence for an epigenetic regulation, perhaps mediated by microRNA's (miRNAs).$^{49}$ The role of inactivation of repressor genes has also been recently documented as before said. ${ }^{23}$

\section{New players: micro-RNA's and the BCL11A enhancer}

A major step in the elucidation of basic cellular processes regulation has been the discovery and the characterization of miRNAs. They are a class of naturally occurring, small noncoding RNA molecules, about 21-25 nucleotides in length, which act as potent negative regulators of gene expression and can modulate the translation of hundreds of genes. ${ }^{50}$ MiRNA's play also a powerful role in hematopoiesis, where they have been implicated in cell fate specification, proliferation, differentiation, etiology and neoplastic progression. In fact it has been recently stated that virtually every step in hematopoiesis seems to be finely tuned by specific miRNA. ${ }^{51}$

It is of special interest for the present review that several miRNAs have been implicated in the developmental progression of globin gene expression and, particularly, in the reactivation of $\gamma$-globin gene expression associated with increased fetal hemoglobin synthesis. For instance, two miRNAs, miR-26b and miR-151-3p, have been studied. While expression of miR-26b was directly associated with HbF levels, expression of miR-151-3p was not associated with $\mathrm{HbF}$ at baseline but was significantly up-regulated by $\mathrm{HC}$ and significantly associated with $\mathrm{HC}$-mediated $\mathrm{HbF}$ induction. It appears therefore that miR-26b may be associated with regulatory mechanisms of $\mathrm{HbF}$, whereas miR-151-3p may be associated with pharmacologic induction of $\mathrm{HbF}$ by hydrox- 
yurea. ${ }^{52}$ More recently, a good deal of research has been performed on another miR, namely miR-486-3p which interacts with the QTL BCL11A by binding to the extra-long isoform of BCL11A 3 UTR. Overexpression of miR-486-3p in erythroid cells resulted in reduced BCL11A protein levels and was associated to increased expression of $\gamma$-globin gene, whereas inhibition of physiological miR-486-3p levels increased BCL11A and thus reduced $\gamma$-globin expression. These findings indicate that miR486-3p contributes to $\mathrm{HbF}$ regulation by posttranscriptional inhibition of BCL11A expression during adult erythropoiesis and it has been thus possible to speculate whether miR486-3p, by intervening in $\mathrm{HbF}$ modulation, might be a contributing factor in determining the different $\mathrm{HbF}$ levels observed among $\beta$-thalassemia patients. ${ }^{53}$

Recent research has been performed to elucidate the mechanism of BCL11A silencing of $\mathrm{HbF}$ production, which appears one of the major players in $\mathrm{Hb}$ switching. It has thus been possible by a genome wide associated study, to characterize common SNPs in the BCL11A gene, which are linked with mild increases in $\mathrm{HbF}$ amounts and are situated within a tissue and developmental stage-specific BCL11A enhancer. ${ }^{54}$ Furthermore, genome engineering reveals that this enhancer is essential for erythroid expression of BCL11A, as its disruption impairs BCL11A expression in erythroid precursors with resultant $\mathrm{HbF}$ derepression, while sparing BCL11A expression in non-erythroid lineages, like B-lymphoid cells. It is therefore suggested that the GWAS identified enhancer of BCL11A might be a promising therapeutic target for genome engineering in the $\beta$-hemoglobinopathies: in that case there would be a planned rational intervention, which would mimic some protective genetic variation. ${ }^{54}$

Mention should be finally made of possible functional links between the master regulator of erythrocyte development and function (GATA-1) and BCL11A-dependent mechanisms. It has been recently claimed that GATA1 , as critical determinant of hemoglobin synthesis, may form a basic regulation core, on which additional mechanisms, like those involving BCL11A, are integrated to yield the complete regulatory system..$^{5}$

\section{Analytical issues on fetal hemoglobin determination}

In most of the laboratories, $\mathrm{HbF}$ is measured by HPLC or by capillary electrophoresis, and the quantification by other techniques, such as radial immunodiffusion or alkali denaturation test is only limited to few laboratories, mostly for research purposes. A recent document produced by the International Committee for the
Standardization in Hematology may be useful to have some more detailed information on the techniques available so far. ${ }^{56}$

Up to now there is no international standardization program for $\mathrm{HbF}$, and no quality specifications have been reported, although these have been defined for other hemoglobin, such as glycated hemoglobin ${ }^{57}$ and total hemoglobin. ${ }^{58}$ Therefore, it is important to outline criteria used for measurement units and the reference interval for the expression of $\mathrm{HbF}$. A uniform measurement unit, used worldwide, is the relative percentage of total hemoglobin, although this is not in line with the International System of Units. Every professional laboratory should build its own reference interval, by measuring $\mathrm{HbF}$ in at least 100 adults, who are not iron-depleted and not carriers of $\alpha$ or $\beta$-thalassemia. It is generally assumed that $\mathrm{HbF}$ above $1 \%$ in a healthy adult individual could be due either to a genetic defect or to some acquired condition. A review on this topic has been proposed recently as a guide for the interpretation of clinical $\mathrm{HbF}$ data and a valuable aid to correct diagnosis..$^{59}$

Finally, the state-of-the-art of the HbF measurement can be evaluated by carefully looking to the External Quality Assessment Schemes (EQAS) report. The data obtained in a large National program, coordinated by the Regional EQAS Service in Tuscany, prove that $\mathrm{HbF}$ is measured with an interlaboratory variability (expressed in terms of coefficient of variation) between 12 to $29 \%$, for samples with $\mathrm{HbF}$ values around $2 \%$, and between 7 to $9 \%$, for samples with $\mathrm{HbF}$ values around 5\% (Ceriotti $\mathrm{F}$, personal communication, 2014). Certainly the quality of the $\mathrm{HbF}$ measurements would have to be improved if particular attention should have to be given to small changes in the $\mathrm{HbF}$ expression level, especially at the $\mathrm{HbF}$ concentrations normally found in healthy people.

\section{Conclusions}

Research in recent years has produced a remarkable improvement in our knowledge of the mechanisms governing the perinatal switch from fetal to adult hemoglobin. It appears now possible to try a reactivation of $\mathrm{HbF}$ production in adult life by planned intervention at molecular level, following the results previously obtained with drugs like decitabine and $\mathrm{HC}$ in certain hemoglobin disorders.

In this context major attention is at present focused on three major loci, which have been shown to be involved in that physiological process. Among these, the quantitative trait locus BCL11A is particularly under scrutiny, as it does not only play a crucial role as normal repressor of $\mathrm{HbF}$ production, but also because it has been experimentally possible to block its effect and thus restore HbF synthesis. A specific enhancer of this gene has also been discovered, which affects the erythropoietic lineage and can therefore be targeted without altering the effect of BCL11A on other tissues. This raises the expectation that in a not distant future a selective restoration of $\mathrm{HbF}$ synthesis in patients affected by severe hemoglobinopathies, like $\beta$-thalassemia or SCD, can be achieved with considerable hematological and clinical benefit.

\section{References}

1. Dover GJ, Boyer SH. Quantitation of hemoglobins within individual red cells: asynchronous biosynthesis of fetal and adult hemoglobin during erythroid maturation in normal subjects. Blood 1980; 56:1082-91.

2. Marti HR, Buetler R. Hemoglobin F and hemoglobin A2 increase in the Swiss population. Acta Haematol 1961;26:65-74.

3. Thein SL, Sampietro M, Rohde K, et al. Detection of a major gene for heterocellular hereditary persistence of fetal hemoglobin after accounting for genetic modifiers. Am J Hum Genet 1994;54:214-28.

4. Weatherall DJ. Phenotype-genotype relationships in monogenic disease: lessons from the thalassaemias. Nat Rev Genet 2001;2:245-55.

5. Bank A. Regulation of human fetal hemoglobin: new players, new complexities. Blood 2006;107:435-43.

6. Loudianos G, Cao A, Ristaldi MS, et al. Molecular basis of $\delta \beta$-thalassemia with normal fetal hemoglobin level. Blood 1990;75:526-8.

7. Tasiopoulou M, Boussiou M, Sinopoulou K, et al. G $\gamma-196 \mathrm{C} \rightarrow \mathrm{T}, \mathrm{A} \gamma-201 \mathrm{C} \rightarrow \mathrm{T}$ : Two novel mutations in the promoter region of the $\gamma$-globin genes associated with nondeletional hereditary persistence of fetal hemoglobin in Greece. Blood Cells Mol Dis 2008;40:320-2.

8. Amato A, Cappabianca MP, Perri M, et al. Interpreting elevated fetal hemoglobin in pathology and health at the basic laboratory level: new and known $\gamma$-gene mutations associated with hereditary persistence of fetal hemoglobin. Int Jnl Lab Hem 2014;36:13-9.

9. Yavarian M, Karimi M, Bakker E, et al. Response to hydroxyurea treatment in Iranian transfusion-dependent $\beta$-thalassemia patients. Haematologica 2004;89:1172-8.

10. Cao A, Galanello R. B-Thalassemia. Genet Med 2010;12:61-76.

11. Wheatherall DJ. Thalassemia: the biogra- 
phy. Oxford: Oxford University Press; 2010.

12. Pembrey ME, Wood WG, Weatherall DJ, Perrine RP. Foetal hemoglobin production and the sickle gene in the oases of Eastern Saudi Arabia. Br J Haematol 1978;40:415-29.

13. El-Hazmi MA, Al-Hazmi AM, Warsy AS. Sickle cell disease in Middle East Arab countries. Indian J Med Res 2011;134:597-610.

14. Platt OS, Brambilla DJ, Rosse WF, et al. Mortality in sickle cell disease. Life expectancy and risk factors for early death. N Engl J Med 1994;330:1639-44.

15. Ngo DA, Aygun B, Akinsheye I, et al. Fetal hemoglobin levels and haematological characteristics of compound heterozygotes for hemoglobin $\mathrm{S}$ and deletional hereditary persistence of fetal hemoglobin. Br $\mathrm{J}$ Haematol 2012;156:259-64.

16. Sankaran VG, Nathan DG. Thalassemia: an overview of 50 years of clinical research. Hematol Oncol Clin North Am 2010;24: 1005-20.

17. Cao A, Rosatelli C, Pirastu M, Galanello R. Thalassemias in Sardinia: molecular pathology, phenotype-genotype correlation, and prevention. Am J Pediatr Hematol Oncol 1991;1:179-88.

18. Charache S, Dover G, Smith K, et al. Treatment of sickle cell anemia with 5 azacytidine results in increased fetal hemoglobin production and is associated with nonrandom hypomethylation of DNA around the $\gamma$ - $\delta$ - $\beta$-globin gene complex. Proc Natl Acad Sci U S A 1983;80:4842-6.

19. Saunthararajah Y, Molokie R, Saraf S, et al. Clinical effectiveness of decitabine in severe sickle cell disease. Br J Haematol 2008;141:126-9.

20. Yavarian MM, Karimi ME, Bakker E, et al. Response to hydroxyurea treatment in Iranian transfusion-dependent $\beta$-thalassemia patients. Haematologica 2004.89: 1172-8.

21. Vasavda N, Woodley C, Allman M, et al. Effects of co-existing $\alpha$-thalassaemia in sickle cell disease on hydroxycarbamide therapy and circulating nucleic acids. Br J Haematol 2012;157:249-52.

22. Cokic VP, Smith RD, Beleslin-Cokic BB, et al. Hydroxyurea induces fetal hemoglobin by the nitric oxide-dependent activation of soluble guanylyl cyclase. J Clin Invest 2003;111:231-9.

23. Flanagan JM, Steward S, Howard TA, et al. Hydroxycarbamide alters erythroid gene expression in children with sickle cell anaemia. Br J Haematol 2012;157:240-8.

24. De Andrade TG, Peterson KR, Cunha AF, et al. Identification of novel candidate genes for globin regulation in erythroid cells containing large deletions of the human $\beta$ globin gene cluster. Blood Cells Mol Dis 2006;37:82-90.

25. Chakalova L, Osborne CS, Dai YF, et al. The
Corfu $\delta$ - $\beta$ thalassemia deletion disrupts $\gamma$ globin gene silencing and reveals posttranscriptional regulation of $\mathrm{HbF}$ expression. Blood 2005;105:2154-60.

26. Bank A. Regulation of human fetal hemoglobin: new players, new complexities. Blood 2006;107:435-43.

27. Uda M, Galanello R, Sanna S, et al. Genome-wide association study shows BCL11A associated with persistent fetal hemoglobin and amelioration of the phenotype of $\beta$-thalassemia. Proc Natl Acad Sci U S A 2008;105:1620-5.

28. Ballas SK, Talacki CA, Adachi K, et al. The Xmn I site (-158, C-T) $5^{\prime}$ to the $\mathrm{G} \gamma$ gene: correlation with the Senegalese haplotype and $\mathbf{G} \gamma$ globin expression. Hemoglobin 1991;15:393-405.

29. Sampietro M, Thein SL, Contreras M, Pazmany L. Variation of $\mathrm{HbF}$ and F-cell number with the G- $\gamma$ Xmn I (C-T) polymorphism in normal individuals. Blood 1992;79:832-3.

30. Silver N, Best S, Menzel S, et al. Quantitative trait locus on chromosome 8q influences the switch from fetal to adult hemoglobin. Blood 2004;104:2184-6.

31. Danjou F, Anni F, Galanello R. B-thalassemia: from genotype to phenotype. Haematologica 2011;96:1573-5.

32. Garner C, Mitchell J, Hatzis T, et al. Haplotype mapping of a major quantitative-trait locus for fetal hemoglobin production, on chromosome 6q23. Am J Hum Genet 1998;68:1468-74.

33. Thein SL, Menzel S, Peng X, et al. Intergenic variants of HBS1L-MYB are responsible for a major quantitative trait locus on chromosome 6q23 influencing fetal hemoglobin levels in adults. Proc Natl Acad Sci U S A 2007;104:11346-51.

34. Thein SL, Menzel S, Lathrop M, Garner C. Control of fetal hemoglobin: new insights emerging from genomics and clinical implications. Hum Mol Genet 2009;18: R216-23.

35. Liu P, Keller JR, Ortiz M, et al. Bcll1a is essential for normal lymphoid development. Nat Immunol 2003;4:525-32.

36. Satterwhite E, Sonoki T, Willis TG, et al. The BCL11 gene family: involvement of BCL11A in lymphoid malignancies. Blood 2001;98:3413-20.

37. Sankaran VG, Xu J, Ragoczy T, et al. Developmental and species-divergent globin switching are driven by BCL11A. Nature 2009;460:1093-7.

38. Xu J, Peng C, Sankaran VG, et al. Correction of sickle cell disease in adult mice by interference with fetal hemoglobin silencing. Science 2011;334:993-6.

39. Menzel S, Garner C, Gut I, et al. A QTL influencing $\mathrm{F}$ cell production maps to a gene encoding a zinc-finger protein on chromosome 2p15. Nat Genet 2007;39: 1197-9.

40. Galanello R, Sanna S, Perseu L, et al. Amelioration of Sardinian $\beta 0$ thalassemia by genetic modifiers. Blood 2009;114:3935-7.

41. Gallienne AE, Dreau HM, Schuh A, et al. Ten novel mutations in the erythroid transcription factor KLF1 gene associated with increased fetal hemoglobin levels in adults. Haematologica 2012;97:340-3.

42. Xu J, Bauer DE, Kerenyi MA, et al. Corepressor-dependent silencing of fetal hemoglobin expression by BCL11A. Proc Natl Acad Sci U S A 2013;11:6518-23.

43. Costa FC, Fedosyuk H, Chazelle AM, et al. Mi2 $\beta$ is required for $\gamma$-globin gene silencing: temporal assembly of a GATA-1-FOG-1$\mathrm{Mi} 2$ repressor complex in $\beta$-YAC transgenic mice. PLoS Genet 2012;8:e1003155.

44. Bradner JE, Mak R, Tanguturi SK, et al. Chemical genetic strategy identifies histone deacetylase 1 (HDAC1) and HDAC2 as therapeutic targets in sickle cell disease. Proc Natl Acad Sci U S A 2010;107: 12617-22.

45. Eridani S, Mosca A. Fetal hemoglobin reactivation and cell engineering in the treatment of sickle cell anemia. J Blood Med 2011;2:23-30.

46. Helin K, Dhanak D. Chromatin proteins and modifications as drug targets. Nature 2013;502:480-8.

47. Wagner JM, Hackanson B, Lübbert M, Jung M. Histone deacetylase (HDAC) inhibitors in recent clinical trials for cancer therapy. Clin Epigenetics 2010;1:11736.

48. Moreira LS, De Andrade TG, Albuquerque $\mathrm{DM}$, et al. Identification of differentially expressed genes induced by hydroxyurea in reticulocytes from sickle cell anaemia patients. Clin Exp Pharmacol Physiol. 2008;35:651-5.

49. Walker AL, Steward S, Howard TA, et al. Epigenetic and molecular profiles of erythroid cells after hydroxyurea treatment in sickle cell anemia. Blood 2011;118:5664-70.

50. Garzon R, Croce CM. MicroRNAs in normal and malignant hematopoiesis. Curr Opin Hematol 2008;15:352-8.

51. Bissels U, Bosio A, Wagner W. MicroRNAs are shaping the hematopoietic landscape. Haematologica 2012;97:160-7.

52. Sankaran VG, Xu J, Orkin SH. Advances in the understanding of hemoglobin switching. Br J Haematol 2010;149:181-94.

53. Lulli V, Romania P, Morsilli 0 , et al. MicroRNA-486-3p regulates $\gamma$-globin expression in human erythroid cells by directly modulating BCL11A. PLoS One 2013;8:e60436.

54. Bauer DE, Kamra S, Lessar S, Xu J, et al. An erythroid enhancer of BCL11A subject to genetic variation determines fetal 
hemoglobin level. Science 2013;242:253-7.

55. Katsumura KR, De Vilbiss AW, Pope NJ, et al. Transcriptional mechanisms underlying hemoglobin synthesis. Cold Spring Harb Perspect Med 2013;3:a015412.

56. Stephens AD, Angastiniotis M, Baysal E, et al. Wild B onbehalf of the International Council for the Standardisation in Heamatology (ICSH). ICSH recommenda- tions for the measurement of hemoglobin F. Int J Lab Hematol 2011;33:1-7.

57. Braga F, Dolci A, Montagnana M, et al. Revaluation of biological variation of glycated hemoglobin (HbAlc) using an accurately designed protocol and an assay traceable to the IFCC reference system. Clin Chim Acta 2011;412:1412-6.

58. Westgard QC. Desiderable biological varia- tion database specifications. Available from: http://www.westgard.com/biodatabase1.htm

59. Mosca A, Paleari R, Leone D, Ivaldi G. The relevance of hemoglobin $\mathrm{F}$ measurement in the diagnosis of thalassaemias and related hemoglobinopathies. Clin Biochem 2009;42:1797-801. 